\title{
Biobanks in South Africa: A global perspective on privacy and confidentiality
}

\author{
R Rheeder, ThD \\ Department of Theology, School of Ecclesiastical Studies, North-West University, Potchefstroom, South Africa
}

Corresponding author: R Rheeder (riaan.rheeder@nwu.ac.za)

\begin{abstract}
The Universal Declaration of Bioethics and Human Rights (UDBHR) of the United Nations Educational, Scientific and Cultural Organization (UNESCO) was adopted unanimously in 2005 by the world community as a universal guideline, according to which members of the global community were accountable to each other. Research results from UNESCO show that the UDBHR has had little or no impact in South Africa (SA). The primary objective of this article is to promote awareness of the UDBHR in SA and Africa by focusing on Article 9 of the Declaration, which accepts the right to privacy and confidentiality. For this objective to be relevant in the SA context, depends on whether the guidelines of the National Department of Health's Ethics in Health Research: Principles, Processes and Structures of 2015 acknowledge biobanks of the universally accepted ethical guidelines on privacy and confidentiality of autonomous persons and whether these guidelines are broadly in accordance with global bioethical guidelines.
\end{abstract}

S Afr Med J 2017;107(5):390-393. DOI:10.7196/SAMJ.2017.v107i5.12004

In this study, Article 9 of the Universal Declaration on Bioethics and Human Rights (UDBHR) of the United Nations Educational, Scientific and Cultural Organization (UNESCO) is investigated to understand and promote the global bioethical norms of privacy and confidentiality. Under the heading 'Privacy and confidentiality', Article 9 reads as follows: 'The privacy of the persons concerned and the confidentiality of their personal information should be respected. To the greatest extent possible, such information should not be used or disclosed for purposes other than those for which it was collected or consented to, consistent with international law, in particular international human rights law. ${ }^{[1]}$

The UDBHR is, in my opinion, one of the most important instruments in the development of human rights and bioethics, as the international community, comprising 191 member states, accepted it unanimously in 2005. This means that the declaration was the first global political and bioethical text to which all the governments in the world, including South Africa (SA), committed themselves. It is the only bioethical document that is so widely accepted. ${ }^{[2-4]}$ The primary aim of this article is to promote awareness of the UDBHR in SA and Africa. Article 23 of the UDBHR makes an appeal to states that have signed the Declaration to promote the principles of Article 9 by means of education in all areas. Mathooko and Kipkemboi, ${ }^{\left[{ }^{[5]}\right.}$ two UDBHR researchers from Africa, are convinced that bioethical teaching is necessary on this continent. The research focus arises from UNESCO research results, showing that the UDBHR has had little or no impact in SA ${ }^{[6]}$ To bring the primary objective of creating awareness of the UDBHR in SA into effect, UNESCO's understanding of respect for the principle of privacy and confidentiality is explained briefly. It is also important to consider that the promotion of human rights awareness in SA depends on all citizens' understanding of and concurrence with the fundamental content of the UDBHR. With regard to the latter, in contrast to all other bioethical instruments, the UDBHR is definitely aimed at developing countries. ${ }^{[1]}$

Several biobanks that function globally have come into existence, also in SA. In June 2010, the National Institutes of Health (USA) and Wellcome Trust (UK) lodged a project, Human Heredity and Health in Africa (H3Africa), with four biobanks in SA. Biobanks are repositories that store human biological materials for research purposes specifically. These banks do not only store organised collections of human biological materials (usually from a large number of donors), but also associated data, including individual health records and information derived from their analysis. ${ }^{[1,2]}$ Several ethical issues are closely related to the phenomenon of biobanks, i.e. informed consent, privacy and confidentiality, sharing of benefits, and many other ethical challenges. It is surmised that there are $>12$ biobanks of different sizes in $\mathrm{SA},{ }^{[7-9]}$ but there is currently no national instrument that focuses exclusively on the ethics of biobanks. The National Health Act No. 61 of 2003 offers no ethical guidelines for biobanks; ${ }^{[9]}$ therefore, the only national document that is currently directional in this regard is the Ethics in Health Research: Principles, Processes and Structures of 2015, updated from the 2004 guidelines ${ }^{[7,10]}$ of the Department of Health $(\mathrm{DoH})$. In the Foreword and Acknowledgements, this document expresses its status as the national policy for conducting research responsibly and ethically, as mandated by Section 72 of the National Health Act No. 61 of 2003. ${ }^{[10]}$

To make the primary goal of the article relevant to the SA context, I discuss whether the guidelines of the $\mathrm{DoH}$ with regard to biobanks incorporate the universally acknowledged ethical guidelines on privacy and confidentiality (of autonomous persons) and whether these guidelines are broadly in accordance with global bioethical guidelines. Commentators of the UDBHR also discuss biobanks in the light of Article 9. ${ }^{[11]}$ In the Handbook of Global BioEthics, ${ }^{[5]}$ which uses the UDBHR as a frame of reference, it is stated that legislation or bioethical instruments in Africa (and by implication in SA) do not conform to international bioethical standards.

Consequently, attention is given to Article 9 of the UDBHR; thereafter, the ethical guidelines of the DoH are discussed briefly to determine whether they are broadly in accordance with global bioethical guidelines. 


\section{Global guidelines}

In the first instance, the UDBHR relates human dignity and privacy/ confidentiality to each other. According to Article 3 of the UDBHR, respect for privacy and confidentiality gives expression to human dignity; where these principles are respected, people are treated with human dignity ${ }^{[12-15]}$ From the following statement it is clear that UNESCO wanted to formalise these principles: 'Nevertheless, in order to use "dignity" in our lives, some practical principles were established. ${ }^{[13]}$

In the second instance, privacy or confidentiality is the direct outcome of autonomy, which deals (according to Article 5 of the UDBHR) with the global recognition that a human being has the right to determine the content of his life. ${ }^{[12]}$

In the third instance, what is UNESCO's interpretation of the concept of 'privacy of the persons'? In their explanation of Article 9, both Stiennon ${ }^{[14]}$ and Martin ${ }^{[15]}$ who analyse the UDBHR, use the definition of the International Bioethics Committee (IBC) of UNESCO as found in UNESCO's Explanatory Memorandum on the Elaboration of the Preliminary Draft Declaration on Universal Norms on Bioethics ${ }^{[4]}$ of June 2005: 'A right to privacy guarantees a control over personal information in many ways. It restricts access to personal and medical information and it provides a claim of non-interference in various private spheres of the individual. Privacy extends beyond data protection, as certain private spheres of the individual that are not manifested in data processing can also be protected by the right to privacy.'

The first fundamental distinguishing norm of the right to privacy is the recognition or confirmation that every individual has a personal space in which he or she has an autonomous decision-making right. ${ }^{[11,14]}$ This personal space includes the whole person (including biological, psychological, social, cultural and spiritual dimensions and all types of data; see Foreword of the UDBHR ${ }^{[1,13]}$ ) and no one has the right to enter the personal space (the claim of non-interference) and remove and use any material or information of the person. ${ }^{[12]}$ Only the person has the right to free his or her space from privacy. This private space of persons (who have the capacity to make autonomous decisions) is protected or held private by the right of (informed) consent, which can be summarised as follows (Article 6 of the UDBHR): 'Any preventive, diagnostic and therapeutic medical intervention ... as well as scientific research ... is only to be carried out with the prior, free and informed consent of the person concerned, based on adequate information. ${ }^{\text {?[1,14,15] }}$

The second fundamental distinguishing guideline of the right to privacy is the recognition that every individual also has within his or her personal space multiple spaces over which he or she has an autonomous, decision-making right (see the abovementioned definition on private spheres). Article 9 of the UDBHR restricts the scope of consent or space. This is deduced from the norm that regulates privacy, confidentiality and information: 'The privacy of the persons concerned and the confidentiality of their personal information should be respected. To the greatest extent possible, such information should not be used ... for purposes other than those for which it was collected or consented to. ${ }^{[1,14]}$

From this explanation, it is clear that consent can or must be clearly aimed at a specific goal ('for purposes other than those for which it was ... consented to'). Consent is very specifically applicable to an exact space or spaces within the larger space and does not open up the total personal space..$^{[12,14,15]}$ The following two examples serve as explanation: (i) consent to use blood samples doesn't automatically open the space to psychological information; and (ii) consent to use biological spaces for researching diseases doesn't mean that biological material may be used for creating human embryos. ${ }^{[9]}$ Currently, it seems (in line with the draft Declaration on Ethical Considerations Regarding Health Databases and Biobanks of the World Medical Association (WMA ${ }^{[16]}$ and in light of the UDBHR's Article 9) as if a concept such as broad informed consent could be problematic, as it cannot be specific. Broad consent permits donor use of biological materials for future studies, subject only to further prior ethics review and approval..$^{[10,13]}$

In the fourth instance, what is UNESCO's understanding of the concept of confidentiality? In their discussion of this concept, both Stiennon ${ }^{[14]}$ and Martin ${ }^{[15]}$ use the definition in the abovementioned explanatory memorandum of the IBC: 'Confidentiality refers to a special and often fiduciary relationship, such as that between researcher and research subject, or doctor and patient, and provides that the shared information shall remain secret, confidential and shall not be disclosed to third persons, unless a strictly defined, compelling interest justifies disclosure under domestic law. ${ }^{\text {[4] }}$

The first basic norm with regard to the concept of confidentiality is that the person is and remains the lawful and autonomous owner of all information that has been attained and moved from the private space. ${ }^{[14]}$ This ownership is quite clear from the following UNESCO statement: "Individuals "own" their information: it is essential to their personal integrity. ${ }^{[12,13]}$ It also means that a person has the right not to know and may request not to be informed about a certain situation. After death, a person also has the right to privacy and confidentiality. ${ }^{\text {[15] }}$

The second basic norm is that if a person or persons want to share information with others outside the initial consent situation, he, she or they have to obtain consent to or exemption from specific confidentiality again. Article 9 states clearly that information should not be used or disclosed for purposes other than those for which it was collected or consented to. ${ }^{[1]}$ From this, it is clear that consent consists of two phases. In a 'first consent', information that has a specific purpose is entrusted to a very clear, demarcated space. If someone wants to move this information from the first space for which consent has been given (whatever the reason might be), a 'second consent opportunity' is necessary. ${ }^{[14,15]}$ Currently, it also seems (in line with the WMA Draft Declaration on Ethical Considerations Regarding Health Databases and Biobanks ${ }^{[16]}$ and in light of the UDBHR's Article 9) as if a concept such as broad informed consent could be contentious in this case.

In the fifth instance, UNESCO recognises that the abovementioned norm is not absolute in all respects and exceptions are possible. The golden rule is that before any confidentiality may be breached, the consent of the patient or substitute must be received. ${ }^{[12]}$ Article 9 regulates that confidentiality should be respected to the greatest extent possible. ${ }^{[1]}$ It means that in exceptional cases, it is permissible that the right to confidentiality could be infringed upon. These exceptions are described as follows in Article 27 of the UDBHR: 'If the application of the principles of this Declaration is to be limited, it should be by law, including laws in the interests of public safety, for the investigation, detection and prosecution of criminal offences, for the protection of public health or for the protection of the rights and freedoms of others. Any such law needs to be consistent with international human rights law. ${ }^{[1,14]}$

Martin $^{[15]}$ asserts that the interest and wellbeing of the community may not easily be used as an argument to justify unlawful infringement of the right to privacy and confidentiality. Article 3.2 of the UDBHR motivates this truth in the following way: 'The interests and welfare of the individual should have priority over the sole interest of science or society. ${ }^{[1]}$ It means that the respect for privacy and confidentiality of the person has greater weight than the interests of science and the community. For now, it would appear as if the UDBHR's possible 
exception only considers public safety, crime tracing and protection of public health (e.g. a highly infectious disease) to infringe upon the right to privacy and confidentiality, and does not really leave room for the argument of broad consent with a view to research or the promotion of the common good of the community.

In the sixth instance, what is the implication of Article 9 as universal bioethical principle and human right? Article 9 states clearly that the right to privacy and confidentiality must be respected. ${ }^{[1]}$ The concept of 'respect' has the meaning of 'protection' within the framework of the Declaration and Article 9. ${ }^{[14]}$ These meanings are confirmed by one of the objectives of the UDBHR, i.e. 'to promote respect for human dignity and protect human rights by ensuring respect for the life of human beings and fundamental freedoms, consistent with international human rights law' (Article 2, c). ${ }^{[1]}$ This protection can be by means of legislation, policy, instruments in the field of bioethics (Article 2), ethics committees (Article 19) and education in bioethics (Article 23) ${ }^{[1]}$ These guidelines refer to both the subject (participant) and the object (researcher) in the context of medical care and research. ${ }^{[1,14]}$

\section{Department of Health guidelines}

The DoH's ethical guidelines with regard to biobanks, privacy and confidentiality are discussed briefly. In paragraph 3.5, which deals with special topics, the DoH pays attention to the following issues: databases, registries and repositories, including biobanks (3.5.2.2). As paragraph 3.5 deals very concisely with biobanks (repositories), relevant information is collected from the entire document. ${ }^{[10]}$ The following conclusions can be drawn:

1. The DoH states clearly in Chapter 2 (Guiding principles for ethical research) that broad ethical principles form the foundation of norms: 'This chapter sets out the broad principles underpinning research that inform the norms and standards. The specific, relevant broad or underlying principle to which the DoH refers is 'respect of persons' that is described as human dignity and autonomy (2.1).

2. In close relation to this principle, the DoH's guidelines state in Chapter 2 that privacy and confidentiality are two key norms and basic rights that flow from the respect for people (human dignity and autonomy): 'The key ethical norms and standards are ongoing respect for participants, including privacy and confidentiality' (2.3; 2.3.7). SA has a long history of recognising the right to privacy and confidentiality in common law ${ }^{[17]}$ and the Constitution. ${ }^{[17]}$ These two principles also form part of the HPCSA's rules and guidelines for healthcare professionals in SA. ${ }^{[18]}$

3. The DoH's guidelines ${ }^{[10]}$ provide the following definitions of these two key ethical norms:

- Simply stated, privacy is concerned with who has access to personal information and records about the participant, including clinical health care records $(2.3 .7 ; 3.1 .8)$.

- However, 'confidentiality' is about ensuring that appropriate measures will be implemented to prevent disclosure of information that might identify the participant (inadvertently or not), either during the course of the research or afterwards $(2.3 .7 ; 3.1 .8)$.

4. It is stated clearly that the privacy and confidentiality of participants in research must be protected:

- Thus researchers and research ethics committees (RECs) should pay careful attention to measures that will protect privacy and confidentiality interests $(2.3 .7 ; 3.1 .8 ; 3.5 .2 .3)$.

5. The different possible ways in which privacy and confidentiality of the participants must be protected are indicated briefly:

- In general terms, a person should know what information is being collected, why it is being collected, what will happen to it, how long it will be retained, whether it will identify the person, whether it will be shared with others and why, whether it will be sent outside SA and why. The person should agree to these terms. $(3.1 .8 ; 3.5 .2 .3)$.

- Broad consent: the donor permits use of the specimen for current research, for storage and possible future research purposes, even though the precise nature of future research may be unclear at present. The nature of the further usage should be described as fully as possible and should stipulate that further prior ethics review of the new study is necessary. Permission may be sought to recontact the person if intended future use is outside the scope of the current consent (3.3.6).

- The Protection of Personal Information Act No. 4 of 2013 (partially in effect) has increased the need to ensure computer safety, locked record storage facilities and careful gate keeping about access to raw data, including completed informed consent documents (3.1.8). It should be remembered that research records, including informed consent documentation, may be solicited by interested parties via application in terms of the Promotion of Access to Information Act No. 2 of 2000.

- Researchers should take measures to ensure privacy and confidentiality interests throughout the research period, including when disseminating results or findings $(2.3 .7 ; 3.1 .8)$.

- Institutions and researchers that maintain repositories (biobanks or tissue banks) must have appropriate facilities, equipment, policies and procedures to store human biological materials and data safely and in compliance with accepted standards (3.5.2.2).

- Appropriate safeguards, including physical, administrative and technical, must exist to protect against unauthorised handling (3.1.8; 3.5.2.2).

- The location, context and timing of recruitment and enrolment should be appropriate for protection of privacy and confidentiality interests (3.1.4).

- The proposal should explain why particular identifying information is required for the study that purports to collect data anonymously (3.1.8).

- RECs should assess whether notifiable activities might occur amongst participants, for example abuse of minors or notifiable diseases and, consequently, whether appropriate measures are in place and are explained in the research proposal $(3.1 .8 ; 3.3 .8)$.

- If the information is to be sent outside the Republic, the recipient must assure that the level of protection afforded in that country is commensurate with that expected in SA (3.1.8).

- Information about a person's health or sex life, inherited characteristics and biometric information must be necessary for the research activity (3.1.8).

- Usually, demographic and medical information about the donors is included in the repository, as are codes that link the material to the donors $(3.3 .3 ; 3.5 .2 .1)$.

- Anonymised materials without any linkage to donors are unlikely to identify a donor (3.3.3).

- Materials collected without identifiers of any kind are unlikely to identify an individual donor (3.3.3).

- The consent documentation for donors should explain clearly ... the conditions and requirements under which data or material will be shared with other researchers.(3.5.2.3).

- The consent documentation for donors should explain clearly ... information about the length of storage time ... [and] when the current consent to use material or data will expire (3.5.2.3).

- If a translator will be used in the consent process and be present for the discussions, the information materials should state that privacy will be compromised to that extent (4.5.1.9). 


\section{Conclusion}

It is clear that the international community has respect for privacy and confidentiality as independent rights and that it regards respect for these rights as an obligation of all communities. In summary, the conclusion can be drawn that the ethical guidelines of the $\mathrm{DoH}$, which also apply to biobanks and research, are broadly in line with the universal guidelines as spelled out in the UDBHR. Both documents take human dignity and autonomy as a point of departure, from which the norms of privacy and confidentiality flow, and they both state categorically that privacy and confidentiality must be protected. I am of the opinion that there is also a broad but definite agreement regarding the understanding of privacy, as both documents state that improper access to the person (implied space) is ethically unacceptable and that access to privacy is protected by informed consent. With regard to confidentiality, the documents state that information will be kept secret and may not be disclosed without consent. They also state that privacy and confidentiality are possibly not absolute and can be ignored in highly exceptional circumstances. It must also be mentioned that the SA Constitution recognises the rights of individuals as being paramount, except where it is 'reasonable and justifiable' to limit them. ${ }^{[17,18]}$ The UDBHR, though, places greater emphasis on the right of the individual than on that of the community, whereas the DoH does not mention anything specific on the matter.

In my view, the DoH meets objective 2(d) of the UDBHR as follows: 'to recognize the importance of freedom of scientific research ... while stressing the need for such research and developments to occur within the framework of ethical principles set out in this Declaration and to respect human dignity, human rights and fundamental freedoms. ${ }^{\text {'[1] }}$ It is therefore incorrect to state that national policies in SA are not in concurrence with global guidelines regarding the regulation of research and biobanks. Nevertheless, the guidelines of the DoH must only be understood as a temporary document with specific shortcomings. For example, no attention is given to the issue of what the ethical implications will be if a biobank has to close prematurely or unexpectedly owing to financial problems, which will give creditors the right to sell assets and trustees to disregard previous contracts, or if no attention is paid to material transfer agreements. ${ }^{[10]}$ For the present, it also seems as if the UDBHR does not support the idea of broad 'informed' consent in Article 9, because privacy and confidentiality have to be directed very narrowly (this statement needs further study).

In light of this, the appeal by leading SA bioethicists, jurists and physicians, such as a A Dhai, S Mahomed and I Sanne, can be supported, i.e. that an 'ethico-regulatory framework' that is exclusively focused on biobanks ${ }^{[16]}$ and in concurrence with all the principles of the UDBHR and international guidelines for biobanks should be developed and implemented in SA in the near future. ${ }^{[7-9]}$

Acknowledgements. None.

Author contributions. Sole author.

Funding. None.

Conflicts of interest. None.

1. United Nations Educational, Scientific and Cultural Organization. Universal Declaration on Bioethics and Human Rights. Paris: UNESCO, 2006. http://unesdoc.unesco.org/images/0014/001461/146180e. pdf (accessed 27 March 2017).

pdf (accessed 27 March 2017).
2. International Bioethics Committee. Report of the International Bioethics Committee of UNESCO: On Consent. Paris: UNESCO, 2008. http://unesdoc.unesco.org/images/0017/001781/178124e.pdf (accessed 27 March 2017).

3. Solbakk J. Vulnerability: A futile or useful principle in healthcare ethics? In: Chadwick R, ten Have H, Meslin EM, eds. The Sage Handbook of Health Care Ethics. London: Sage, 2011:228-238.

4. United Nations Educational, Scientific and Cultural Organization. Explanatory Memorandum on the Elaboration of the Preliminary Draft Declaration on Universal Norms on Bioethics. Paris: UNESCO, Elaboration of the Preliminary Draft Declaration on Universal Norms on Bioethics. Paris: UN).
2005. http://unesdoc.unesco.org/images/0013/001390/139024e.pdf (accessed 27 March 2017).

5. Mathooko J, Kipkemboi J. African perspectives. In: Ten Have H, Gordijn B, eds. Handbook of Global Bioethics. Dordrecht: Springer Science and Business Media, 2014:253-268.

6. Langlois A. Negotiating Bioethics: The Governance of UNESCO’s Bioethics Programme. New York: Routledge, 2013:1-192.

7. Dhai A. Establishing national biobanks in South Africa: The urgent need for an ethico-regulatory framework. S Afr J Bioethics Law 2013;6(2):38-39. https://doi.org/10.7196/sajbl.296

8. Dhai A, Mahomed S, Sanne I. Biobanks and human health research: Balancing progress and protections. S Afr J Bioethics Law 2015;8(2)55. https://doi.org/10.7196/SAJBL.8060
.

9. Dhai A, Mahomed S. Biobank research: Time for discussion and debate. S Afr Med J 2013;103(4):225227. https://doi.org/10.7196/samj.6813

10. Department of Health. Ethics in Health Research: Principles, Processes and Structures. 2nd ed. Pretoria: DoH, 2015. http://sun.ac.za/research/assets/files/Integrity_and_Ethics/DoH\%202015\%20 Ethics\%20in\%20Health\%20Research\%20-\%20Principles,\%20Processes\%20and\%20Structures\%20 2nd\%20Ed.pdf (accessed 27 March 2017).

11. Shickle D. Biobanking. In: Ten Have AMJ, Gordijn B, eds. Handbook of Global Bioethics. Dordrecht: Springer Science and Business Media, 2014:485-503.

12. United Nations Educational, Scientific and Cultural Organization. Bioethics Core Curriculum, Section 1. Syllabus: Ethics Education Programme. Paris: UNESCO, 2008. http://unesdoc.unesco.org/ images/0016/001636/163613e.pdf (accessed 27 March 2017).

13. United Nations Educational, Scientific and Cultural Organization. Casebook on Human Dignity and Human Rights, Bioethics. Core Curriculum Casebook Series, No. 1. Paris: UNESCO, 2011. http:// unesdoc.unesco.org/images/0019/001923/192371e.pdf (accessed 27 March 2017).

14. Stiennon J-A. Article 9: Privacy and confidentiality. In: Ten Have AMJ, Jean MS, eds. The UNESCO Universal Declaration on Bioethics and Human Rights: Background, Principles and Application (Ethics Series). Paris: UNESCO, 2009:165-172.

15. Martin JF. Privacy and confidentiality. In: Ten Have AMJ, Gordijn B, eds. Handbook of Global Bioethics. Dordrecht: Springer Science and Business Media, 2014:119-137.

16. World Medical Association. WMA Declaration on Ethical Considerations Regarding Health Databases and Biobanks: A Draft from the Work Group Intended for Open Consultation After Acceptance of the Executive Committee of the WMA. Ferney-Voltaire: WMA, 2015. http://wma.net/en/20activities/10et hics/15hdpublicconsult/2015-Draft-policy-HDB_BB.pdf (accessed 27 March 2017).

17. Dhai A, McQuoid-Mason D. Confidentiality. In: Dhai A, McQuoid-Mason D, eds. Bioethics, Human Rights and Health Law: Principles and Practice. Claremont: Juta, 2011:88.

18. Health Professions Council of South Africa. Guidelines for Good Practice in the Health Care Professions. Confidentiality: Protecting and Providing Information, Booklet 10. Pretoria: HPCSA, 2008. http://hpcsa. co.za/Uploads/editor/UserFiles/downloads/conduct_ethics/rules/generic_ethical_rules/booklet_10_ confidentiality_protecting_and_providing_information.pdf (accessed 17 January 2017).

Accepted 25 January 2017 